\title{
Skull Fracture and Haemorrhage Pattern among Fatal and Nonfatal Head Injury and Primary Reconstruction of Depressed Fracture
}

\author{
Aly HM Omar ${ }^{1}$, Morid M Hanna ${ }^{1}$, Manal A Abdel Zaher ${ }^{1}$, Ghada A Ishak ${ }^{1}$, Ayman L Fahim ${ }^{2 *}$ \\ ${ }^{1}$ Department of Forensic and Clinical Toxicology, Minia University, Egypt \\ ${ }^{2}$ Institute of Forensic Medicine, Minia University, Egypt \\ *Corresponding author: Ayman L Fahim, Forensic Physician, Institute of Forensic Medicine, Egypt, Tel: +962792836851; E-mail: dr_aymanlatif@yahoo.com
}

Received date: March 26, 2018; Accepted date: April 14, 2018; Published date: April 21, 2018

Copyright: @ 2018 Omar AHM, et al. This is an open-access article distributed under the terms of the Creative Commons Attribution License, which permits unrestricted use, distribution, and reproduction in any medium, provided the original author and source are credited.

\begin{abstract}
Head injuries is a worldwide problem. It is defined as insult to the head region and include fractures of the skull and facial bone. intracranial injuries and injuries to a special sense. The important factor that determines the outcome is terms of survival of such head injury cases include the type of weapon used, type and site of skull fracture, intracranial haemorrhage. The study concluded a total of 206 cases with criminal head injury. All cases were from Minia Govern rate, Egypt. Age was ranged from 11 to 80 years old. In the current study the cases were with a definite head injury. Cases examined for age, sex, residence, type and site of fracture, treatment and complication. Cases were divided into 2 groups first group was patients with head injury and stay alive (non-fatal group) second group was patients with head injury and died at once after trauma or on their way to the hospital or after admission to the hospital (fatal group). Complete medical examination was done to the first group and complete autopsy was done to the second group, cross tabulations of the two groups for each variable were statistically analysed such variables include age, residence, sex, type of trauma, effect of trauma, treatment and complications. Chi square test was done to compare categorical variables with a $P$ value $<0.05$ is considered significant, ANOVA test was done to compare the age variable between the 2 examined groups. SPSS version 16 was used for statistical analysis, firearm injuries were the major cause of such criminal assault followed by injuries due to blunt trauma among fatal cases meanwhile blunt trauma was the common type of such criminal assault among non-fatal cases. Chance of survival following blunt trauma to the head is far greater as shown in the present study, light weapons are not sufficient to inflict fatal head injury, there was significant difference between both sex regarding fatality and outcome of head injuries, increasing age associated with poor outcome, the incidence of head injuries was very high in rural areas compared with urban areas and the mortality rate in rural areas was very high due to lack of facilities and all cases were referred to contral hospitals, the comminuted skull fracture was the commonest fatal type, the extradural and subdural haemorrhage were more common among the non-fatal cases and subarachnoid haemorrhage was more common among fatal cases.
\end{abstract}

Keywords: Head injuries; Skull fracture; Intracranial haemorrhage; Brain trauma

\section{Introduction}

Head injury refers to trauma to the head which may or may not include the brain. It may result from closed or open penetrating injuries, and is an important cause of morbidity and mortality worldwide. Thousands of patients are affected annually with young males mostly involved probably due to increased activity associated with this group. Common etiologic factors of head injury include road traffic accidents, assaults, fall from height and stab wounds [1].

Penetrating head injuries have higher mortality and morbidity than blunt trauma even in civilian setup. Case fatality rates are higher for penetrating than closed injuries for all age, gender, and cause of injury. Most common sites for entry wound are the temporal area and orbit where the bone is thin [2].

Fractures of the skull can be divided into either fractures of the vault or the base of the skull. Such fractures are quite common and are important to acknowledge. Vault fractures are common. They can be further divided into either open or closed and depressed or non depressed fractures. Fractures of the vault have a tendency to cause epidural haemorrhage. These epidural hematomas may be arterial or venous in nature. Usually, the arterial hematomas are caused by bony specula from the fracture tearing the middle meningeal artery. The venous hematomas are usually secondary to oozing from the fracture edges and have a tendency to expand slower than the arterial hematomas [3].

Traditional management of compound depressed skull fractures entails elevation and removal of all bone fragments with delayed cranioplasty. The closed depressed skull fractures (CDSFs) are usually treated non operatively because surgery offers little if any benefit in most cases. The only indication described for surgical repair of CDSF is the presence of hematoma, obvious dural disruption, and poor cosmetic appearance [4].

\section{Subjects and Methods}

\section{Subjects}

A total of 206 cases with criminal head injury were included in the study. The study was conducted in Minia forensic medicine department, Minia Governrate, Egypt. Age of cases was ranged from 11:80 years $(41 \pm 16.5)$. Cases from both sex were included in a ratio of 10 male: 1 female. The study was carried out all over a period of three years from January 2012 to December 2014. 
Page 2 of 4

Cases only with a definite documentation of the injury were included in the study. Documentation of the injury was through medical reports, eye witness of from police reports and from the proper detailed autopsy examination in died cases. All cases suffered from head injury due to an attack, without injury to other parts of the body.

\section{Methods}

Cases were divided into two groups:-

Group (I): Non-fatal head injury cases.

Group (II): Fatal head injury cases.

The following items have been full field in every case as follow:-

Age - sex - residence - type of trauma - effect of trauma - treatment if done - if done - fate and complications.

1) For group (1)

Complete medical examination of each case separately was done in El Minia forensic department.

Collection of medical reports from the hospitals

Complete recorded investigations including (X-ray and CT scan).

Any neurosurgical advisory.

2) For group (2)

Complete autopsy was done to all cases either at once after infliction of the trauma or those who died at the hospital. Autopsy was carried out carefully to avoid any artifacts with an enough observation of the attached meninges and adequate examination of the vault and base for the presence of fracture (Table 1).

\begin{tabular}{|l|l|l|l|}
\hline & Group (1) & Group (2) & P \\
\hline Male & $86(45.9 \%)$ & $101(54.1 \%)$ & \multirow{2}{*}{0.096} \\
\cline { 1 - 4 } Female & $10(52.6 \%)$ & $9(47.4 \%)$ & \\
\hline
\end{tabular}

Table 1: Showing gender distribution among the two examined groups, $\mathrm{P}$ value $\leq 0.05$ is considered significant, Group 1: non-fatal cases; Group 2: fatal cases.

The examined variables were statistically analysed by Chi-square test to compare categorical variables between the two examined groups. ANOVA test was used to compare the age variable between the examined groups. P value $\leq 0.05$ is considered significant. A statistical software (SPSS) version 16 was used for statistical analysis (Table 2).

\begin{tabular}{|l|l|l|c|}
\hline & Group (1) & Group (2) & \multicolumn{1}{|c|}{ P } \\
\cline { 1 - 2 } Blunt & $94(66.2 \%)$ & $48(33.8 \%)$ & \\
\cline { 1 - 2 } Fire arm (bullet) & $0(0 \%)$ & $50(100 \%)$ & \multirow{2}{*}{$<0.01^{* *}$} \\
\cline { 1 - 2 } Fire arm (shots) & $2(33.3 \%)$ & $6(66.7 \%)$ & \\
\cline { 1 - 3 } Cut contused & $0(0 \%)$ & $6(100 \%)$ & \\
\hline
\end{tabular}

Table 2: Showing the type of trauma among the two examined groups, $\mathrm{P}$ value $\leq 0.05$ is considered significant, Group 1: non-fatal cases; Group 2: fatal cases.

\section{Results}

Among the whole examined cases 96 cases were of a non-fatal head injury, on the other hand the fatal head injury cases were 110, either died at once or in their way to the hospital or after hospital admission.

\section{Discussion}

Estimates indicate that $50 \%$ of trauma related deaths are the result of head trauma. Most head injuries are transportation related. Recently, however, violence-related head injury has become such a concern. Computed tomography or magnetic resonance imaging is the preferred diagnostic imaging study. Unfavourable outcomes are associated with age [5].

The present study clearly showed the predominant usage of firearms and their effectiveness as a murder weapons, and this was in agreement with Memchoubi et al. [6], who also reported that firearms were the most common murder weapon in their study.

The current results revealed insignificant difference between both sex regarding the fatality and outcome of head injuries this is in agreement with Ji-Yao [7], who found that gender does not affect mortality of acute head trauma patients.

The recent study found that male cases were $(90.7 \%)$ of all cases owing to increased incidence of fights between males compared to females in a matter coinciding with Ming-Fu et al. [8], who reported that males had more head injuries than females. Also this was in agreement with Sachin et al. [9], who found that $74 \%$ of patients were males and $26 \%$ were females. The male:female ratio was 3:1 attributed to more outdoor exposure in males and hence increased vulnerability to fall and accidents and fights.

The incidence of head injuries was very high in rural areas (77\%) compared with urban areas $(23 \%)$ and this was also associated with increased mortality rate (61.6\%) in rural areas versus $(25.5 \%)$ in urban areas. This was referred to the increased usage of firearm weapons in rural areas than in urban ones, this is in agreement with Ming-Fu et al. [8], who reported that the incidence was near 2 folds higher in the rural areas than in the urban areas. The high mortality rate in rural areas may be also due to lack of facilities and surgeons in rural medical centers (Table 3 ).

\begin{tabular}{|l|l|l|l|l|l|}
\hline & Blunt & $\begin{array}{l}\text { Firearm } \\
\text { (bullet) }\end{array}$ & $\begin{array}{l}\text { Firearm } \\
\text { (shots) }\end{array}$ & $\begin{array}{l}\text { Cut } \\
\text { contused } \\
\text { wound }\end{array}$ & P \\
\hline Rural & $99(62.4 \%)$ & $48(30 \%)$ & $6(3.8 \%)$ & $6(3.8 \%)$ & \multirow{2}{*}{$0.02^{* *}$} \\
\hline Urban & $43(92.4 \%)$ & $2(3.8 \%)$ & $2(3.8 \%)$ & 0 & \\
\hline
\end{tabular}

Table 3: Showing type of trauma in relation to residence, $P$ value $\leq 0.05$ is considered significant.

Blunt trauma was the most common type and had the highest survival rate $(66.2 \%)$. Firearm injuries had the highest mortality rate between all types of head injuries and this is in agreement with Saurabh and Chandrabhall [10], who reported that among the fatal cases, firearm was the most common assault weapon and was followed by the blunt instrument (Table 1). 
Citation: Omar AHM, Hanna MM, Zaher MAA, Ishak GA, Fahim AL (2018) Skull Fracture and Haemorrhage Pattern among Fatal and Nonfatal Head Injury and Primary Reconstruction of Depressed Fracture. J Forensic Med 3: 122. doi:10.4172/2472-1026.1000122

Page 3 of 4

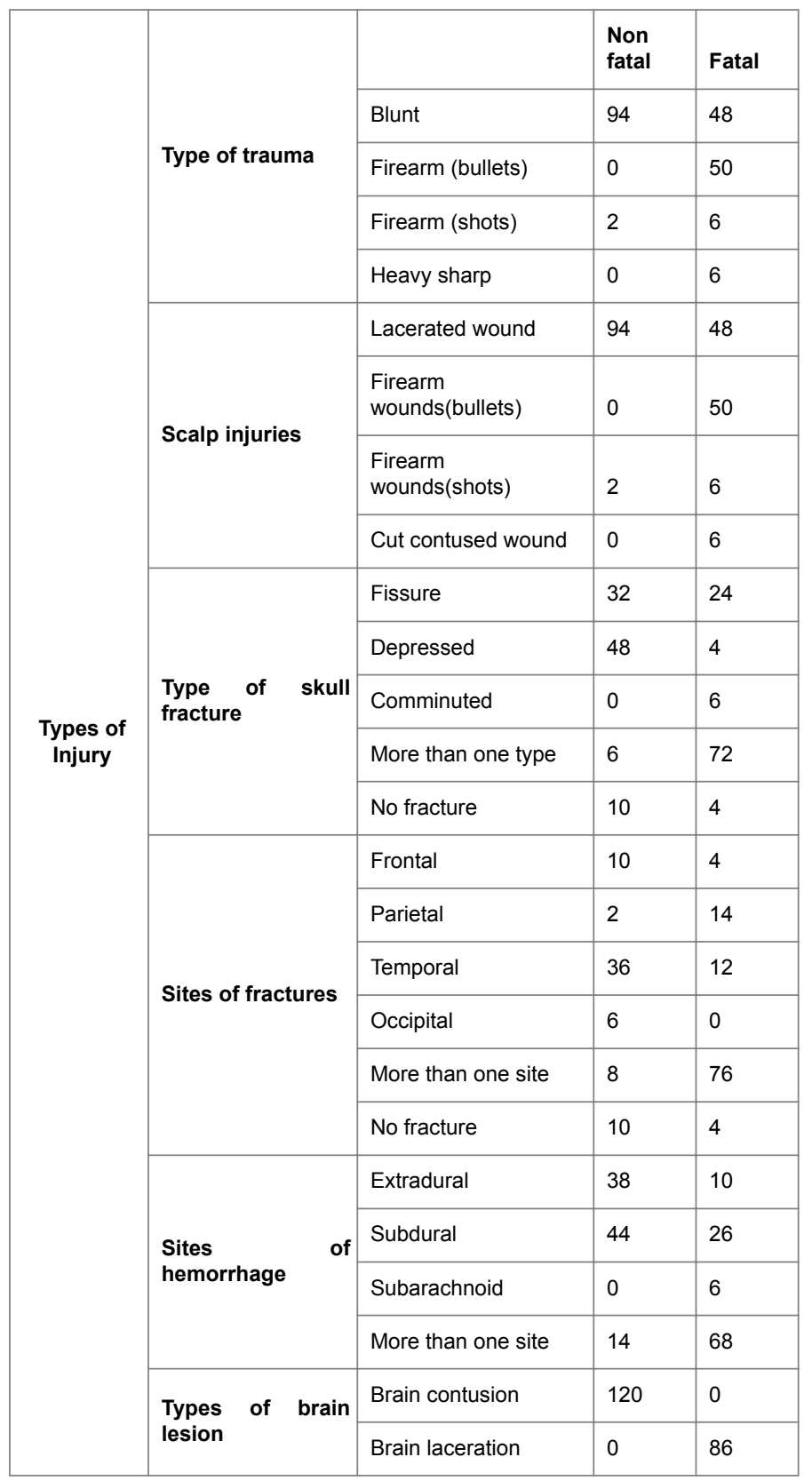

Table 4: Showing distribution of types of injuries among the two groups.

The current study showed that the comminuted fracture of the skull was the commonest fatal type of skull fracture among fatal cases. All cases of comminuted fracture died at once, and this was due to the accompanied brain laceration, this is in agreement with Henry [11], who found that all cases with skull fractures and/or significant brain injury were considered a fatal injury (Table 4 ).

The present study showed that the cases with depressed fracture were occupying the higher incidence among the escaped cases, especially those with temporal and parietal fractures, McHugh et al. [12], reported that isolated skull fractures are not rather threatening injuries and by itself have few clinical consequence, except in cases of basal skull fractures involving cerebral vessels (Table 5).

\begin{tabular}{|l|l|l|c|}
\hline & Group (1) & Group (2) & \multirow{2}{*}{ P } \\
\hline Fissure & $32(57.1 \%)$ & $24(42.9 \%)$ & \\
\cline { 1 - 3 } Depressed & $48(92.3 \%)$ & $4(7.7 \%)$ & \multirow{2}{*}{$<0.01^{* *}$} \\
\cline { 1 - 3 } Comminuted & $0(0 \%)$ & $6(100 \%)$ & \\
\cline { 1 - 3 } More than one type & $6(7.7 \%)$ & $72(92.3 \%)$ & \\
\cline { 1 - 2 } No fractures & $10(71.4 \%)$ & $4(28.6 \%)$ & \\
\hline
\end{tabular}

Table 5: Showing the type of fracture among the two examined groups, $P$ value $\leq 0.05$ is considered significant.

The present study showed that extradural and subdural hemorrhage were more common among the non-fatal cases (Table 6). On the other hand subarachnoid hemorrhage and cases with more than on site hemorrhage were more common among the fatal cases. Hence it could be said that the deeper the hemorrhage in the cranial cavity, the greater the incidence of fatality (Table 7).

\begin{tabular}{|l|l|l|l|}
\hline & Group (1) & Group (2) & \multirow{2}{*}{ P } \\
\hline Extradural & $38(79.2 \%)$ & $10(20.8 \%)$ & \\
\cline { 1 - 3 } Subdural & $44(62.8 \%)$ & $26(37.2 \%)$ & \multirow{2}{*}{$<0.01^{* *}$} \\
\cline { 1 - 3 } Subarachnoid & $0(0 \%)$ & $6(100 \%)$ & \\
\cline { 1 - 3 } More than one site & $14(17.1 \%)$ & $68(82.9 \%)$ & \\
\hline
\end{tabular}

Table 6: Showing the type of haemorrhage among the two examined groups, $\mathrm{P}$ value $\leq 0.05$ is considered significant.

\begin{tabular}{|l|l|l|c|}
\hline & Complications & $\begin{array}{l}\text { No } \\
\text { complications }\end{array}$ & P \\
\hline $\begin{array}{l}\text { Conservative } \\
\text { treatment }\end{array}$ & 18 & 20 & $<0.01^{* *}$ \\
\cline { 1 - 3 } Trephine & 28 & 0 & \\
\hline
\end{tabular}

Table 7: Showing the fate of treatment in the lived groups as regard incidence of complications.

\section{Conclusion and Recommendation}

The present study showed that there was a higher incidence of all types of head trauma in El Minia governorate and also showed a higher incidence of firearm head injuries.

As found in the present study, the fatality rate was (53.4\%) among the whole examined victims. Firearm injuries were the major cause of such criminal assaults, in a matter referred to the wide spread usage of such weapons. The blunt and sharp weapons were the most commonly reported cause of head and face injuries.

Firearm injuries were the common injuries among the fatal cases (50.9\%) and always accompanied by brain laceration followed by blunt injuries (43.6\%). Blunt injuries were the common injuries in non fatal cases $(97.9 \%)$ which resulted in depressed fracture as the commonest type of fracture $(50 \%)$. Single cranial bone fracture was noted among the majority of the survivors $(83.3 \%)$. 
Citation: Omar AHM, Hanna MM, Zaher MAA, Ishak GA, Fahim AL (2018) Skull Fracture and Haemorrhage Pattern among Fatal and Nonfatal Head Injury and Primary Reconstruction of Depressed Fracture. J Forensic Med 3: 122. doi:10.4172/2472-1026.1000122

Page 4 of 4

The present study clearly showed the predominant usage of firearms and their effectiveness as a murder weapons. Subsequently, the study recommends strict adequate firm regulations to usage of such weapons.

More researches must be carried out on cases with comminuted skull fractures and or subarachnoid hge as a trial to discover new methods of treatment to decrease mortality in such cases as those also represent a highest mortality rate between all types of head injuries.

The present study revealed that there is no surgical treatment by primary reconstruction in Minia governorate hospitals, the treatment was done by doing only trephine operation leaving a bone gap and this is not in agreement with Nayak and Mahapatra [13], who said that the concept of primary reconstruction was to close the defect and preserve the anatomical barrier, to prevent further complications.

The study recommended training of the neurosurgeon in El Minia University hospital to do decompressive craniotomy with primary reconstruction of skull bone to decrease complications.

\section{References}

1. Adeyekun AA, Egbedi-Ejakpovi EB (2013) Computerised tomographic patterns in patients with head injury at the University of Benin Teaching Hospital. Niger J Clin Pract 16: 19-22.

2. Gopalakrishnan M, Indira D (2007) Fatal penetrating orbitocerebral injury by bicycle brake handle. Indian J Neurotrauma 4: 123-124.
3. André P (2012) Management of severe traumatic brain injury. Acta Neurologica Scandinavica 128: 220- 227.

4. Donovan DJ (2005) Simple depressed skull fracture causing sagittal sinus stenosis and increased intracranial pressure. Surg Neurol 63: 380-383.

5. Kalb S, Theodore N (2014) Head Injuries. In: Mark G, Volker KH Sonntag (Eds), Encyclopedia of the Neurological Sciences. 2nd edition, Servier INC.

6. Memchoubi PH, Momonchand A, Fimate L (2003) Homicides in and around Imphal. J Indian Acad Forensic Med 25: 13-15.

7. Ji-yao J (2013) Head trauma in China. Int J Care Injured 44: 1453-1457.

8. Ming-Fu C, Wen-Ta C, Jasmine H, Wan-Lin C, Shu-Fen C, et al. (2006) Head injuries in adolescents in Taiwan: a comparison between urban and rural groups. J Surg Neurol 66: 14-19.

9. Sachin A, Sumit S, Deepak A, Guru D, Deepak G, et al. (2011) Severe head injury in the elderly: risk factor assessment and outcome analysis in a series of 100 consecutive patients at a Level 1 trauma centre. Indian J Neurotrauma, 8: 77-82.

10. Saurabh C, Chandrabhal T (2010) Skull fracture and haemorrhage pattern among fatal and nonfatal head injury assault victims. J Inj Violence Res 2: 99-103.

11. Henry J (2009) Brain trauma in head injuries presenting with and without concurrent skull fractures. J Forensic Leg Med 16: 115-120.

12. McHugh GS, Engel DC, Butcher I (2007) Prognostic value of secondary insults in traumatic brain injury: results from the impact study. J Neurotrauma 24: 287-293.

13. Nayak PK, Mahapatra AK (2007) Primary reconstruction of depressed skull fracture. Indian J Neurotrauma, 5: 35-38. 